\title{
Critical Congenital Heart Disease Newborn Screening Implementation: Lessons Learned
}

\author{
Monica R. McClain ${ }^{1}$, John S. Hokanson², Regina Grazel ${ }^{3}$, Kim Van Naarden Braun ${ }^{4}$, \\ Lorraine F. Garg ${ }^{3}$, Michelle R. Morris ${ }^{5}$, Kathleen Moline ${ }^{5}$, Keri Urquhart ${ }^{6}$, Amy Nance ${ }^{7}$, \\ Harper Randall ${ }^{7}$, and Marci K. Sontag ${ }^{8}$ \\ ${ }^{1}$ Institute on Disability, University of New Hampshire, 10 West Edge Drive, Suite 101, Durham, NH \\ 03824, USA \\ 2University of Wisconsin-Madison, Madison, WI, USA \\ ${ }^{3} \mathrm{New}$ Jersey Department of Health, Trenton, NJ, USA \\ ${ }^{4}$ Centers for Disease Control and Prevention, Atlanta, GA, USA \\ ${ }^{5}$ Virginia Department of Health, Richmond, VA, USA \\ ${ }^{6}$ Michigan Department of Community Health, Lansing, ME, USA \\ ${ }^{7}$ Utah Department of Health, Salt Lake City, UT, USA \\ 8University of Colorado Anschutz Medical Center, Denver, CO, USA
}

\section{Abstract}

Introduction-The purpose of this article is to present the collective experiences of six federallyfunded critical congenital heart disease (CCHD) newborn screening implementation projects to assist federal and state policy makers and public health to implement CCHD screening.

Methods-A qualitative assessment and summary from six demonstration project grantees and other state representatives involved in the implementation of CCHD screening programs are presented in the following areas: legislation, provider and family education, screening algorithms and interpretation, data collection and quality improvement, telemedicine, home and rural births, and neonatal intensive care unit populations.

Results-The most common challenges to implementation include: lack of uniform legislative and statutory mandates for screening programs, lack of funding/resources, difficulty in screening algorithm interpretation, limited availability of pediatric echocardiography, and integrating data collection and reporting with existing newborn screening systems. Identified solutions include: programs should consider integrating third party insurers and other partners early in the legislative/ statutory process; development of visual tools and language modification to assist in the

Correspondence to: Monica R. McClain.

Electronic supplementary material The online version of this article (doi:10.1007/s10995-017-2273-4) contains supplementary material, which is available to authorized users.

Disclaimer The views and conclusions expressed in this report are those of the authors and do not necessarily represent the official position of the Centers for Disease Control and Prevention, HRSA, or HHS. 
interpretation of algorithms, training programs for adult sonographers to perform neonatal echocardiography, building upon existing newborn screening systems, and using automated data transfer mechanisms.

Discussion-Continued and expanded surveillance, research, prevention and education efforts are needed to inform screening programs, with an aim to reduce morbidity, mortality and other adverse consequences for individuals and families affected by CCHD.

\section{Keywords}

Critical congenital heart disease; Newborn screening; Public health

\section{Introduction}

Congenital malformations are one of the leading causes of infant death in the United States (U.S.), and critical congenital heart disease (also referred to as critical congenital heart defects [CCHD]) is responsible for more deaths than any other type of malformation (Hoffman and Kaplan 2002; Reller et al. 2008). It is estimated that approximately two of every 1000 live births will have CCHD; these conditions require surgery or catheter intervention during the first year of life (Mahle et al. 2009). Some cases are detected by a prenatal ultrasound; others may be detected on the basis of physical examination findings (e.g., heart murmurs, rapid breathing, respiratory distress, or blue skin) in the newborn, yet not all infants with CCHD are identified prior to hospital discharge (4-31\%) (Brown et al. 2006; Liberman et al. 2014; Peterson et al. 2014a), which may result in significant morbidity or mortality. Pulse oximetry has been implemented as a point-of-care newborn screening test for CCHD, to identify these undiagnosed cases (Mahle et al. 2009). Performed 24-48 h after birth, pulse oximetry screening is a non-invasive measurement of the proportion of hemoglobin in blood that is saturated with oxygen. The presence of low blood oxygen saturation (hypoxemia), or a difference between pre-ductal and post-ductal (proximal and distal to the aortic opening of the ductus arteriosus, respectively) saturation, frequently precedes other signs or symptoms in infants with unrecognized CCHD (Kemper et al. 2011).

The primary targets of CCHD screening are seven specific lesions: (1) hypoplastic left heart syndrome, (2) pulmonary atresia, (3) tetralogy of Fallot, (4) total anomalous pulmonary venous return, (5) transposition of the great arteries, (6) tricuspid atresia, and (7) truncus arteriosus (Kemper et al. 2011). An additional five cardiac malformations (coarctation of the aorta, Ebstein's anomaly of the tricuspid valve, interruption of the aortic arch, double outlet right ventricle, and other single ventricle heart disease) have been detected in pulse oximetry screening studies less consistently, and may be included by screening programs as secondary targets [Mahle et al. 2009]. The screening characteristics (e.g. detection rate, false negatives) vary by CCHD type.

As part of the Newborn Screening Saves Lives Act of 2008, the Secretary's Advisory Committee on Heritable Disorders in Newborns and Children (SACHDNC) was established to reduce morbidity and mortality in newborns and children that have, or are at risk for, heritable disorders (Appendix 1) (Hoffman et al. 2002). Following an evidence review process, SACHDNC recommended to the Secretary of Health and Human Services to add 
CCHD to the Recommended Uniform Screening Panel (RUSP) for NBS (Secretary's

Advisory Committee on Heritable Disorders in Newborns and Children 2015); the Secretary adopted the recommendation in September 2011 (Sebelius 2011), which was endorsed by the American Academy of Pediatrics (Mahle et al. 2012). In her recommendation, the Secretary charged the Health Resources and Services Administration (HRSA) to develop screening standards and infrastructure needed for a public health approach for point-of-care CCHD screening.

In response to the Secretary's charge, HRSA funded six CCHD screening demonstration projects (funding ( $\$ 300,000$ per year) for a 3 year period, June 2012-May 2015). These projects were charged to support the development, dissemination and validation of screening protocols and infrastructure needs for point-of-care screening specific to CCHD. The six funded programs were: (1) Michigan; (2) New Jersey; (3) Utah; (4) Virginia; (5) Wisconsin; and (6) a consortium of five New England states (Maine, New Hampshire, Vermont, Rhode Island, and Connecticut). The purpose of this report is to present the collective experiences of these grantees, highlight issues that may be important to those interested in CCHD screening programs, and describe the successes and challenges to assist policy makers and public health programs that are considering, or are in early stages of, CCHD screening implementation.

\section{Methods}

In HRSA's Funding Opportunity Announcement (Catalog of Federal Domestic Assistance number 93.110), each of the grantees was required to: (1) create a network including the state public health department, hospitals and/or birth facilities; (2) develop a plan to incorporate CCHD screening and reporting at the provider and state levels; (3) develop guidelines to collect and report results of CCHD screening to stakeholders (e.g. state public health department, families); (4) develop and deliver educational programs about CCHD screening, counselling, testing, followup, treatment and specialty services to parents, families, and patient advocacy and support groups, (5) perform quality assurance, outcomes analyses, cost analysis, and other public health monitoring functions; (6) establish guidelines for follow-up methodology and reporting; (7) coordinate with Maternal and Child Health Bureau-funded programs; and (8) establish, operate, and maintain a state-level electronic system to systematically collect and analyze data, and evaluate the impact of CCHD screening (e.g., proportion of babies screened prior to discharge, number of CCHD cases detected by screening, health care utilization). In 2013, the Newborn Screening Technical assistance and Evaluation Program (NewSTEPs) began hosting a monthly technical assistance conference call for individuals interested in CCHD screening, and in February 2014, partnered with the Pediatric Congenital Heart Association to convene an in-person meeting to discuss the current status of CCHD screening in the U.S., and to provide ideas and guidance for screening programs across all stages of implementation. The grantees and other leaders in CCHD screening shared challenges and successes with invited representatives. Following the February meeting, continued education efforts include monthly webinars and several video conferencing sessions for all demonstration projects, hosted by Virginia's CCHD Screening Program. This report is a product of these collaborations. 


\section{Results}

\section{Legislation and Sustainability}

While the SACHDNC recommends that all conditions listed in the RUSP be integrated in every newborn screening program, which conditions each state includes, as well as their process for adding conditions, varies; some require legislation, while others use a regulatory process. State requirements for implementation and the status of states that have adopted CCHD screening as of March 12, 2015 are available (Appendix 1) (Reller et al. 2008;

Glidewell et al. 2015). Legislative and statutory mandates for screening, data collection and reporting processes and requirements for state newborn screening programs are not uniform. A number of state programs lack the public health authority to collect data on individual newborns, underscoring the importance of ensuring that data collection is included in the legislative language.

A common challenge of adding new disorders to screening programs is a lack of funding and other resources. Most screening programs use newborn screening fees to support broad program activities. Some stakeholders pursued a fee increase via legislation or other regulatory mechanisms to support CCHD screening implementation. In addition, some programs have explored non-traditional funding approaches such as tobacco taxes. Further, for both initial implementation challenges as well as long term sustainability, programs should consider integrating third party insurers and other partners early in the developmental process. Finally, adoption of a Current Procedural Terminology (CPT) code from the American Medical Association could also help to sustain CCHD screening by providing unique reimbursement.

\section{Screening Algorithms and Interpretation}

The recommended screening algorithm endorsed by the American Academy of Pediatrics (AAP) (Kemper et al. 2011) (Appendix 2) has been widely adopted. Some states (e.g., New Jersey) (Garg et al 2015) and birthing facilities have developed alternative algorithms to improve the outcomes of the screening algorithm locally. As screening implementation has occurred in many states, questions regarding the most appropriate cut-off values, need for both a pre-ductal and post-ductal reading, best timing of the screen, number of repeat screens, and requirements for failure of the screen have been raised. Studies, including mathematical modelling, are currently underway examining the impact of algorithm modifications on the screening characteristics.

The HRSA grantees commonly received feedback from birth registrars and nurses regarding the screening terminology and algorithm interpretation. This feedback resulted in projects implementing changes to modify the language to "negative/pass" and "positive/fail" to ensure more consistent reporting of CCHD screening results. In particular, recognition that greater than $3 \%$ differential between pre- and post-ductal results constitutes a failed screen has been documented as a common challenge. (Appendix 2). Education efforts and development of an enhanced visual tool based on the screening algorithm were strategies used to improve accuracy of interpretation of CCHD screening results and ease of use for healthcare providers (Fig. 1). 
Children born at high altitude may have lower pulse oximetry levels than those born at sea level; thus there may be more false positives from CCHD screening at higher elevations. Grantees did not directly evaluate this issue. However, research is currently being conducted to determine if screening algorithms should be adjusted, based on elevation. There is evidence that alternative algorithms are warranted at moderate altitudes (2500-5500 feet) [Samuel et al. 2013; Wright et al. 2014).

\section{Provider and Family Education}

Education of both providers and parents is critical for successful implementation of CCHD screening. Comprehensive provider education includes information on benefits and limitations of screening, performing the screening, algorithm interpretation, and short- and long-term followup recommendations. Education for parents and family is necessary to increase awareness of CCHD screening using pulse oximetry and to ensure an understanding that not all CCHDs are detected with the screen (false negatives). Resources with appropriate literacy levels and in languages for the population served have been created by the grantees and others (Appendix 1) (Reller et al. 2008; Mahle et al. 2009; Brown et al. 2006; Liberman et al. 2014; Peterson et al. 2014; Kemper et al. 2011; Secretary's Advisory Committee on Heritable Disorders in Newborns and Children 2015).

\section{Data Collection/Surveillance/Quality Improvement}

During the project period, grantees were required to document and track the numbers of infants (1) screened, (2) with abnormal screens and referred for additional evaluations, (3) diagnosed with CCHD before discharge, and (4) diagnosed with CCHD by one year of age, but not detected via screening (i.e., false negative). Select performance characteristics of pulse oximetry screening for CCHD are summarized in Table 1 . While some programs have some data on the false negatives, none of the programs has complete ascertainment of these cases. Grantees were also required to document and track the costs associated with abnormal screens and the outcomes of those detected infants (alive or deceased, number of hospitalizations, etc.). These data are not reported. Many grantees collected additional data specific to the goals and objectives of their individual projects that will be used to evaluate their screening projects (Table 2). Table 2 also describes various data collection mechanisms; some grantees used more than one mechanism for each data element, and the mechanisms varied among grantees (Table 3 ). The diversity of data collection and reporting methods presents a challenge to comparing data across programs, yet highlights the potential for future collaborative efforts. Table 2 also describes the many lessons learned and numerous ongoing challenges with data collection and reporting. The most common and important challenge is the lack of sustained funding for data collection activities. Some grantees have either ceased data collection activities or significantly reduced the data elements collected when grant funding ended. Further, birth certificates and/or dried blood spot cards often have limited space, therefore states using this method of collection may be restricted to collecting a limited number of fields. Some projects extract data directly from electronic medical records using tools that include labor- and time-intensive spreadsheets and automated (electronic) messaging, i.e., data file transfer. Automated systems that can extract pulse oximeter data from the testing device and transmit it to the medical record are available but not yet in wide use. Building upon existing birth defects registries by adding 
reporting requirements for all failed screens in addition to CCHD diagnoses, as done in $\mathrm{NJ}$, can help facilitate detailed data collection (Garg et al. 2013].

All-payer-claims databases present additional opportunities to locate data on surgical and other interventions for CCHD, including types of surgery, paid amounts and lengths of hospitalizations. If individual level data collection is not feasible, aggregate data can be collected to assess screening coverage and the number of failed screens. Data reporting and tracking may be hampered due to patient mobility, at times across state borders, for surgical and long-term follow-up care. To achieve adequate tracking, stakeholders recommended a memorandum of understanding between border state programs.

In all newborn screening programs, the identification of false negatives is a challenge. However CCHD diagnosis is a reportable condition in many states. Thus, data from birth defects registries and CCHD screening can be linked to help identify false negative screens. Programs can seek further ascertainment of false negatives through collaboration with tertiary care centers. Data collection can be instrumental for quality improvement through state level assessment and feedback of hospital performance and internal hospital audits to monitor missed screens and misinterpretation of the screening algorithm.

\section{Telemedicine and Rural Hospitals}

Newborns with a positive pulse oximetry screen and no other apparent causes of low blood oxygen saturation should have a CCHD diagnosis excluded or confirmed with clinical evaluation and echocardiography. However, echocardiography is not immediately available in all birthing locations, and many states have large geographic areas with limited access to cardiologists. Options for this scenario include echocardiography by telemedicine, mobile echocardiography units, where qualified professionals and equipment travel to the patient, or transferring to another center for evaluation, which adds significantly to the cost of screening and parental anxiety. While the infant may be initially transferred to a hospital with echocardiography capabilities, transfer to a larger hospital with a pediatric cardiac surgeon may be advised to avoid costly delays before appropriate intervention, if needed. The Wisconsin Screening Hearts In NEwborns (SHINE) Project has developed an online course for adult cardiac sonographers who might be called upon to perform neonatal echocardiography (Appendix 1) (Secretary's Advisory Committee on Heritable Disorders in Newborns and Children 2015). This allows providers who complete this training to perform this study on-site, with images read via telemedicine by a pediatric cardiologist. The decision to transport a newborn for further evaluation should be informed by a pediatric cardiology consultation.

\section{Home Births}

In 2012, over 35,000 births occurred at home in the U.S, representing almost $1 \%$ of the U.S. births (Martin et al. 2012). This population has been shown to have more than ten times the incidence of missed CCHD diagnoses than the general population (Ng and Hokansan 2010). This is likely the result of lower use of prenatal ultrasound, shorter postdelivery observation, higher incidences of certain CCHD conditions in populations that are more likely to choose home births (e.g., Amish), and a general reluctance to seek medical care. A recent 
publication from one of the grantees has shown that CCHD screening can be successfully implemented in out-of-hospital births (Lhost et al. 2014). Educating midwives and lay birth attendants and providing them with pulse oximeters may improve the utilization of CCHD screening in home births. An additional challenge raised was that of outreach to unregulated/ unlicensed midwives. Potential solutions are to identify a champion for midwives, provide training on CCHD screening, offer small community service-oriented grants for equipment, and make pulse oximeters available to them.

\section{Neonatal Intensive Care Unit (NICU)}

The Secretary's recommendation to add CCHD to the RUSP is targeted toward newborns in the well-baby nursery and many states are required to screen all infants, including those in the NICU. Currently, there are no recommended algorithms for NICU populations, though one has been examined (Lakshminrusimha et al. 2012). Issues complicating CCHD screening in the NICU include: receipt of oxygen; ranges of gestational age; routine use of pulse oximetry, and type and severity of disease processes, all of which impact the validity of screening. Multiple grantees report differences in NICU screening practices and currently, there are no population-based data to support CCHD screening guidelines for NICU populations. Preliminary data on the NICU population from Wisconsin and New Jersey suggest that the number of failed screens may be minimal. A collaborative effort among five states, led by NJ, is underway to evaluate and inform best screening practices in the NICU by examining timing of screening, screening values, echocardiograms conducted in response to screening results, along with clinical characteristics, such as presence of a prenatal diagnosis and/or echocardiogram prior to the screen.

\section{Discussion}

The six HRSA grantees have identified barriers and solutions to CCHD screening implementation and have provided leadership for the broader CCHD community on how to develop networks among public and private health professionals, professional organizations, family advocates, and other stakeholders to implement and improve CCHD screening programs. As the number of states engaging in CCHD screening has increased dramatically since 2011 (Glidewell et al. 2015), potential solutions to the challenges expressed by the grantees and other state representatives may aid programs to fully implement CCHD screening and to engage in quality improvement activities. The insights provided in this report reflect the experiences of six grantees and complement the significant contributions to our current understanding of CCHD screening implementation made thus far by other organizations and programs (Appendix 1) (Reller et al. 2008; Mahle et al. 2009; Brown et al. 2006; Liberman et al. 2014; Peterson et al. 2014; Kemper et al. 2011; Secretary's Advisory Committee on Heritable Disorders in Newborns and Children 2015).

Implementation and oversight for state-wide CCHD screening resulting from legislation often resides within a state public health agency. Successful implementation of legislatively mandated CCHD screening requires establishment of strong collaboration and ongoing and frequent communication between departments of health, birthing facilities, providers and 
advocacy groups. The greatest benefit has been realized when engagement begins early in the implementation process such that feedback is effectively integrated.

State newborn screening (NBS) and birth defects surveillance programs are uniquely positioned to play key roles in the implementation, maintenance, and on-going assessment of CCHD screening. These two long-standing programs provide potential infrastructure on which to build CCHD screening activities. Nevertheless, birth defects surveillance programs do not exist in all states and funding to support additional activities does not often accompany legislation. One of the challenges in implementing CCHD screening and evaluation of the screening is that in many states the NBS program and birth defect surveillance programs are separate, and may have variable integration. Fostering communication and collaboration between these two stakeholders is an important challenge to consider. Further challenges to implementing CCHD screening include: obtaining resources to provide education and training, as well as to collect, store, and analyze screening data, evaluate missed cases and/or screens (false negative screens or reasons not screened), assess burden and accuracy for failed screens and resulting final diagnoses (CCHD, other cardiac, and non-cardiac), provide long-term follow-up for comprehensive outcomes, and provide data reporting/feed- back to the clinical sites (Olney et al. 2012). Implementation efforts may be limited and sustainability may be a challenge if screening mandates are unfunded. Coordinated sustainability planning can occur with collaboration among third party insurers, local and national funding sources, advocacy groups and state/ local health programs, as well as exploration of unconventional funding mechanisms (e.g. tobacco tax).

Given varied resources for data collection, the collective grantee experience provides guidance on the public health utility of various data elements using a number of collection mechanisms. These mechanisms, the majority of which were supported solely through grant funding, range from aggregate to individual level data collection with elements spanning from, for example, dichotomous pass/fail results to all potential pre- and post-ductal saturations. The benefits and limitations related to the mechanisms and questions that can be answered vary and are heavily dependent on existing infrastructure and additional funding. Accurate and complete data collection was noted by grantees to be enhanced by manual or automated quality control activities at the hospital level.

The grantees' experiences highlighted topics in CCHD screening programs that require further evaluation. Interpretation and potential modification of the screening algorithm needs further study to determine whether both the differential in saturations, as well as the less than $95 \%$ thresholds, are necessary. Data from Minnesota suggest that even minor modifications in the algorithm can have significant impact on re-screening rates (Kochilas et al. 2015). Assessment of the efficacy of CCHD screening including the magnitude of false negatives is needed along with methods for ascertaining these cases. Given the challenges in screening special populations, the most appropriate practices and algorithms for screening home births, NICU, and rural births still need to be thoroughly examined. Finally, additional provider training is needed to ensure appropriate interpretation and implementation of the screening algorithm. Ongoing education will be needed to disseminate new knowledge and evidence as they are discovered. 
Early identification of CCHD is an important clinical and public health issue. CCHD detection utilizing pulse oximeter screening may lead to decreased hospital costs and infant morbidity and mortality. While costs and cost- effectiveness were not addressed as a collaborative effort, there is evidence that screening is cost-effective under a range of circumstances [Peterson et al. 2013a, 2014, 2013b]. Continued and expanded surveillance, research, prevention and communication efforts are needed to inform screening programs, with an aim to reduce morbidity, mortality and other adverse consequences for individuals and families affected by CCHD.

\section{Supplementary Material}

Refer to Web version on PubMed Central for supplementary material.

\section{Acknowledgments}

This project is/was supported by the Health Resources and Services Administration (HRSA) of the U.S. Department of Health and Human Services (HHS) under grant numbers H46MC24058 (Michigan Department of Community Health), H46MC24060 (University of New Hampshire), H46MC24059 (New Jersey Department of Health and Senior Services), H46MC24061 (Utah Department of Health), H46MC24062 (Virginia Department of Health), and H46MC24057 (Board of Regents of the University of Wisconsin System). Each project was awarded $\$ 900,000$, with $0 \%$ financed with nongovernmental sources. Additional funding for this project was supported by HRSA Cooperative Agreement \#U22MC24078 (Association of Public Health Laboratories, NewSTEPs).

\section{References}

Brown KL, Ridout DA, Hoskote A, Verhulst L, Ricci M, Bull C. Delayed diagnosis of congenital heart disease worsens preoperative condition and outcome of surgery in neonates. Heart (British Cardiac Society). 2006; 92(9):1298-1302. [PubMed: 16449514]

Garg LF, Van Naarden Braun K, Knapp MM, et al. Results from the New Jersey statewide critical congenital heart defects screening program. Pediatrics. 2013; 132(2):e314-e323. [PubMed: 23858425]

Glidewell J, Olney RS, Hinton C, et al. State legislation, regulations, and hospital guidelines for newborn screening for critical congenital heart defects - United States, 2011-2014. MMWR Morbidity and Mortality Weekly Report. 2015; 64(23):625-630. [PubMed: 26086632]

Hoffman JI, Kaplan S. The incidence of congenital heart disease. Journal of the American College of Cardiology. 2002; 39(12):1890-1900. [PubMed: 12084585]

Kemper AR, Mahle WT, Martin GR, et al. Strategies for implementing screening for critical congenital heart disease. Pediatrics. 2011; 128(5):e1259-e1267. [PubMed: 21987707]

Kochilas LK, Menk JS, Saarinen A, Gaviglio A, Lohr JL. A comparison of retesting rates using alternative testing algorithms in the pilot implementation of critical congenital heart disease screening in Minnesota. Pediatric cardiology. 2015; 36(3):550-554. [PubMed: 25304248]

Lakshminrusimha S, Turkovich S, Manja V, Nair J, Kumar VH. Critical congenital heart disease screening with pulse oximetry in the neonatal intensive care unit. e-Journal of Neonatology Research. 2012; 2(2):96-101.

Lhost JJ, Goetz EM, Belling JD, van Roojen WM, Spicer G, Hokanson JS. Pulse oximetry screening for critical congenital heart disease in planned out-of-hospital births. The Journal of pediatrics. 2014; 165(3):485-489. [PubMed: 24948344]

Liberman RF, Getz KD, Lin AE, et al. Delayed diagnosis of critical congenital heart defects: trends and associated factors. Pediatrics. 2014; 134(2):e373-e381. [PubMed: 25070301]

Mahle WT, Martin GR, Beekman RH 3rd, et al. Endorsement of health and human services recommendation for pulse oximetry screening for critical congenital heart disease. Pediatrics. 2012; 129(1):190-192. [PubMed: 22201143] 
Mahle WT, Newburger JW, Matherne GP, et al. Role of pulse oximetry in examining newborns for congenital heart disease: a scientific statement from the AHA and AAP. Pediatrics. 2009; 124(2): 823-836. [PubMed: 19581259]

Martin JA, Hamilton BE, Osterman MJ, Curtin SC, Mathews TJ. Births: final data for 2012. National Vital Statistics Report. 2013; 62(9):1-87.

$\mathrm{Ng} \mathrm{B}$, Hokanson J. Missed congenital heart disease in neonates. Congenital Heart Disease. 2010; 5(3): 292-296. [PubMed: 20576049]

Olney RS, Botto LD. Newborn screening for critical congenital heart disease: essential public health roles for birth defects monitoring programs. Birth defects research. Part A, Clinical and Molecular Teratology. 2012; 94(12):965-969. [PubMed: 23184496]

Peterson C, Ailes E, Riehle-Colarusso T, et al. Late detection of critical congenital heart disease among US infants: estimation of the potential impact of proposed universal screening using pulse oximetry. JAMA pediatrics. 2014a; 168(4):361-370. [PubMed: 24493342]

Peterson C, Dawson A, Grosse SD, et al. Hospitalizations, costs, and mortality among infants with critical congenital heart disease: how important is timely detection? Birth Defects Research. Part A, Clinical and Molecular Teratology. 2013a; 97(10):664-672. [PubMed: 24000201]

Peterson C, Grosse SD, Glidewell J, et al. A public health economic assessment of hospitals' cost to screen newborns for critical congenital heart disease. Public Health Reports. 2014b; 129(1):86-93. [PubMed: 24381364]

Peterson C, Grosse SD, Oster ME, Olney RS, Cassell CH. Cost-effectiveness of routine screening for critical congenital heart disease in US newborns. Pediatrics. 2013b; 132(3):e595-e603. [PubMed: 23918890]

Reller MD, Strickland MJ, Riehle-Colarusso T, Mahle WT, Correa A. Prevalence of congenital heart defects in metropolitan Atlanta, 1998-2005. The Journal of pediatrics. 2008; 153(6):807-813. [PubMed: 18657826]

Secretary's Advisory Committee on Heritable Disorders in Newborns and Children. 2015. Retrieved October 9, 2015 from http://www.hrsa.gov/advisorycommittees/mchbadvisory/herita-bledisorders/ recommendedpanel/uniformscreeningpanel.pdf

Samuel TY, Bromiker R, Mimouni FB, et al. Newborn oxygen saturation at mild altitude versus sea level: implications for neonatal screening for critical congenital heart disease. Acta Paediatrica. 2013; 102(4):379-384. [PubMed: 23298328]

Sebelius, K. 2011. Retrieved October 9, 2015 fom:http:/www.hrsa.gov/advisorycommittees/ mchbadvisory/heritabledisorders/rec-ommendations/correspondence/ cyanoticheartsecre09212011.pdf

Wright J, Kohn M, Niermeyer S, Rausch CM. Feasibility of critical congenital heart disease newborn screening at moderate altitude. Pediatrics. 2014; 133(3):e561-e569. [PubMed: 24567022]

Matern Child Health J. Author manuscript; available in PMC 2018 June 01. 


\section{Significance}

This article provides points to consider when implementing critical congenital heart disease newborn screening programs. It also provides resources and potential solutions to challenges experienced by other programs. 

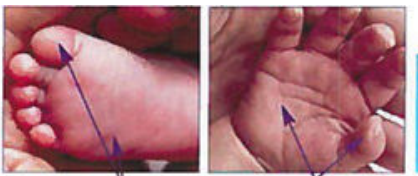

Critical Congenital Heart Disease Screening Table

Foot Application Sites RH Application Sites

\begin{tabular}{|c|c|c|c|c|c|c|c|c|c|c|c|c|}
\hline $\begin{array}{l}\text { Right } \\
\text { Hand }\end{array}$ & \multicolumn{10}{|c|}{ Either Foot } & $<90$ \\
\hline $\mathbf{1 0 0}$ & 100 & 99 & 98 & 97 & 96 & 95 & 94 & 93 & 92 & 91 & 90 & $<90$ \\
\hline $\mathbf{9 9}$ & 100 & 99 & 98 & 97 & 96 & 95 & 94 & 93 & 92 & 91 & 90 & $<90$ \\
\hline $\mathbf{9 8}$ & 100 & 99 & 98 & 97 & 96 & 95 & 94 & 93 & 92 & 91 & 90 & $<90$ \\
\hline 97 & 100 & 99 & 98 & 97 & 96 & 95 & 94 & 93 & 92 & 91 & 90 & $<90$ \\
\hline 96 & 100 & 99 & 98 & 97 & 96 & 95 & 94 & 93 & 92 & 91 & 90 & $<90$ \\
\hline 95 & 100 & 99 & 98 & 97 & 96 & 95 & 94 & 93 & 92 & 91 & 90 & $<90$ \\
\hline 94 & 100 & 99 & 98 & 97 & 96 & 95 & 94 & 93 & 92 & 91 & 90 & $<90$ \\
\hline 93 & 100 & 99 & 98 & 97 & 96 & 95 & 94 & 93 & 92 & 91 & 90 & $<90$ \\
\hline 92 & 100 & 99 & 98 & 97 & 96 & 95 & 94 & 93 & 92 & 91 & 90 & $<90$ \\
\hline 91 & 100 & 99 & 98 & 97 & 96 & 95 & 94 & 93 & 92 & 91 & 90 & $<90$ \\
\hline 90 & 100 & 99 & 98 & 97 & 96 & 95 & 94 & 93 & 92 & 91 & 90 & $<90$ \\
\hline$<90$ & $<90$ & $<90$ & $<90$ & $<90$ & $<90$ & $<90$ & $<90$ & $<90$ & $<90$ & $<90$ & $<90$ & $<90$ \\
\hline
\end{tabular}

PASS-Pulse ox of $95 \%$ or more in RH or foot AND difference of $3 \%$ or less between the two.

Action: Do not repeat for screening. Provide normal newborn care.

RETEST - Pulse ox of $90-94 \%$ in BOTH the RH and foot OR a difference of $4 \%$ or more between the RH and foot.

Action: Repeat pulse ox measurements in one hour.

If the second test remains yellow, repeat again in one hour. If the third test is still yellow, it is a FAIL and should be reported to the medical provider

\section{FAll-Pulse ox of $89 \%$ or less in either the RH or foot.}

Action: Do not repeat, report to medical provider.

Adapted from the Mueller CCHD Screening Chart created by Cynthia Mueller RN, BSN (2013)

Adapted from Strategies for Implementing Screening for Critical Congenital Heart Disease

Kemper A.. et al.. Pediatrics 2011(128)5: el259 - 1267.Kemper A.. et al.. Pediatrics 2011(128)5: el259 - 1267.

\section{VDH}

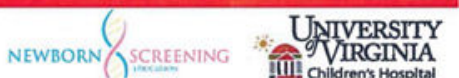

Fig. 1.

A visual tool developed by the state of Virginia to enhance CCHD screening algorithm interpretation 


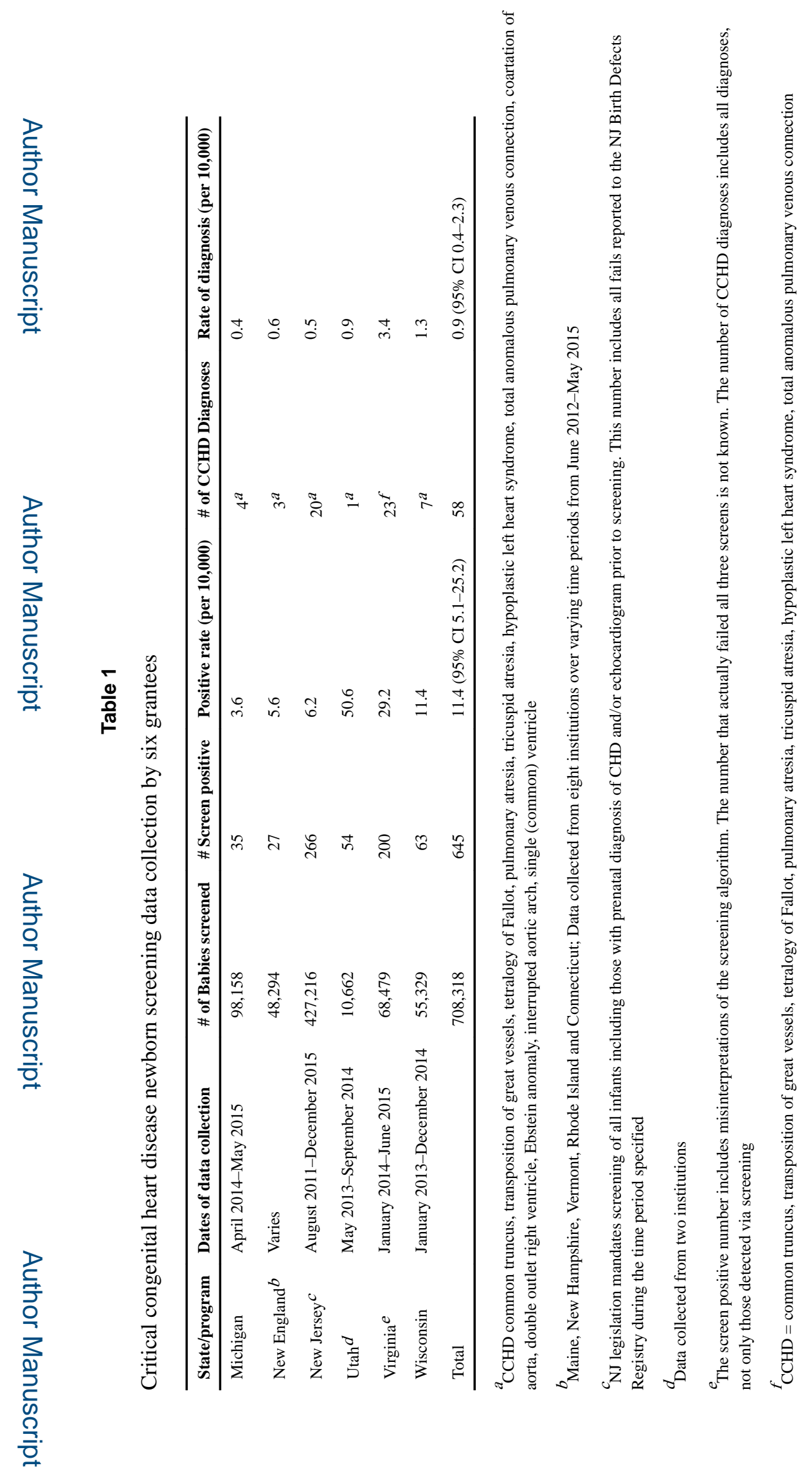

Matern Child Health J. Author manuscript; available in PMC 2018 June 01. 
Table 2

Data and collection mechanism useful in evaluation of CCHD screening by six demonstration project grantees

\begin{tabular}{|c|c|c|}
\hline Data collected by grantees & Collection mechanisms & Area of evaluation \\
\hline \multicolumn{3}{|l|}{ Population characteristics } \\
\hline Number live-births & $\mathrm{EBC}, \mathrm{AG}$ & \multirow[t]{3}{*}{ Screening coverage } \\
\hline Number screened & AG, EMR, HL7, SEM, EBC, BDR, NBC & \\
\hline Reason not screened & AG, EMR, HL7, SEM, EBC, BDR, NBC & \\
\hline \multicolumn{3}{|l|}{ Screening results } \\
\hline Pulse oximetry screen date/time & EMR, HL7, SEM, EBC, BDR, NBC & \multirow{3}{*}{$\begin{array}{l}\text { Screening algorithm performance and } \\
\text { interpretation }\end{array}$} \\
\hline All saturation results & EMR, HL7, SEM, EBC, BDR & \\
\hline Pass/Fail & AG, EMR, HL7, SEM, EBC, BDR, NBC & \\
\hline \multicolumn{3}{|l|}{ Clinical characteristics } \\
\hline Antenatal ultrasound (yes/no) & EMR, HL7, SEM, EBC, BDR & Screening algorithm performance \\
\hline Prenatal CCHD diagnosis & EMR, HL7, SEM, EBC, BDR & \multirow{9}{*}{$\begin{array}{l}\text { Contribution of pulse oximetry screening to } \\
\text { identification of CCHD }\end{array}$} \\
\hline Clinical exam date/time & EMR, HL7, SEM, EBC, BDR & \\
\hline Clinical exam findings & EMR, HL7, SEM, EBC, BDR & \\
\hline Echocardiogram (yes/no) & EMR, HL7, SEM, EBC, BDR & \\
\hline Echocardiogram date/location or prior to screen & EMR, SEM, EBC, BDR & \\
\hline Echocardiogram findings & EMR, SEM, EBC, BDR & \\
\hline Signs or symptoms at the time of screen & EMR, SEM, EBC, BDR & \\
\hline Final diagnosis & EMR, SEM, EBC, BDR & \\
\hline Age at diagnosis & EMR, EBC, BDR & \\
\hline \multicolumn{3}{|l|}{ Follow-up information } \\
\hline Surgery date/hospital & EMR, EBC, BDR & Outcomes \\
\hline Date of death (if applicable) & BDR, Vital Records & \\
\hline
\end{tabular}

$N B C$ newborn bloodspot card, $S P F$ state-specific CCHD paper forms, $S E M$ state-specific CCHD electronic module, $H L 7$ Health level-7 messaging; automatic file transfer, $A G$ aggregate data collection, $E B C$ electronic birth certificate, $B D R$ birth defects registry, $E M R$ hospital electronic medical record 
Table 3

Data collection challenges and lessons learned, by six CCHD demonstration project grantees

\begin{tabular}{|c|c|c|}
\hline $\begin{array}{l}\text { Description of grantees' data collection } \\
\text { activities with demonstration grant } \\
\text { funding }\end{array}$ & Lessons learned & Continuing challenges \\
\hline $\begin{array}{l}\text { Michigan } \\
\text { Funded mandate for screening } \\
\text { Data incorporated into newborn } \\
\text { screening Laboratory Information } \\
\text { Management System } \\
\text { Data collection mechanism: EBC, } \\
\text { EMR, HL7, SEM, BDR } \\
\text { Individual level data collected }\end{array}$ & $\begin{array}{l}\text { Support needed from birthing facilities, IT } \\
\text { departments } \\
\text { Internal quality control (QC) audits needed at } \\
\text { hospital Communication and support from } \\
\text { birthing facilities are crucial to identify and } \\
\text { follow-up on failed, missed and transferred cases } \\
\text { level }\end{array}$ & $\begin{array}{l}\text { Hospital readiness for HL7 submission } \\
\text { Data quality: file transfer, completeness, and } \\
\text { follow-up on missed or failed screens } \\
\text { Obtaining internal and external data use } \\
\text { agreements to evaluate false negatives }\end{array}$ \\
\hline $\begin{array}{l}\text { New England (ME, NH, VT, RI, CT) } \\
\text { NH and CT do not have public health } \\
\text { authority for data collection } \\
\text { Project collected de-identified data } \\
\text { from eight birthing facilities across five } \\
\text { states (two aggregate and six individual- } \\
\text { level) } \\
\text { Data collection mechanism: AG, SPF, } \\
\text { SEM, BDR }\end{array}$ & $\begin{array}{l}\text { Screening at tertiary care centers has a very low } \\
\text { detection rate, likely due to prenatal diagnosis } \\
\text { and clinical diagnosis post-natally prior to } \\
\text { screening } \\
\text { False positive rate is acceptably low Public } \\
\text { health programs and birthing facilities worked } \\
\text { cooperatively across states and shared resources, } \\
\text { expertise and experiences }\end{array}$ & $\begin{array}{l}\text { Data are not collected consistently across } \\
\text { states and are reported in different formats } \\
\text { Algorithm interpretation errors } \\
\text { Home birth and NICU screening data not } \\
\text { collected }\end{array}$ \\
\hline $\begin{array}{l}\text { New Jersey } \\
\text { Unfunded mandate for screening } \\
\text { As of January 2015, individual level } \\
\text { data incorporated into electronic birth } \\
\text { record system } \\
\text { Failed screens reported to NJ Birth } \\
\text { Defects Registry (BDR) } \\
\text { Data collection mechanism: AG, EBC, } \\
\text { BDR }\end{array}$ & $\begin{array}{l}\text { Internal quality control (QC) audits needed at } \\
\text { hospital level } \\
\text { Strong communication and support from } \\
\text { birthing facilities required for implementation } \\
\text { Lack of real time reporting and inability to track } \\
\text { infants across reporting periods with aggregate } \\
\text { data collection } \\
\text { Individual level reporting improves ability to } \\
\text { conduct QC and evaluate false negatives }\end{array}$ & $\begin{array}{l}\text { Identification of false negatives due to tertiary } \\
\text { care provided in bordering states } \\
\text { No direct data input from EMR into electronic } \\
\text { birth certificate and manual data entry } \\
\text { required for individual level reporting } \\
\text { No real-time QC of algorithm interpretation }\end{array}$ \\
\hline $\begin{array}{l}\text { Utah } \\
\text { Unfunded mandate for screening } \\
\text { BDR reporting rule } \\
\text { One year of pilot data with individual } \\
\text { saturation levels from two large hospital } \\
\text { systems } \\
\text { As of October 2014, using EBC to } \\
\text { monitor pass/fail } \\
\text { Link EBC to BDR to confirm true fails } \\
\text { and identify false fails } \\
\text { Data collection mechanism: AG, EBC, } \\
\text { EMR, BDR }\end{array}$ & $\begin{array}{l}\text { Cumbersome for birthing facilities to } \\
\text { incorporate screening results into their current } \\
\text { EMR } \\
\text { Difficulty in data cleaning } \\
\text { EBC reliable for Pass/Fail results and not } \\
\text { onerous for facilities } \\
\text { Need to work with legislature to include } \\
\text { mandated reporting and funding }\end{array}$ & $\begin{array}{l}\text { Reporting errors by EBC clerks } \\
\text { Timing of EBC reporting does not include } \\
\text { NICU results on most babies } \\
\text { Working with home birth providers to screen/ } \\
\text { report } \\
\text { Algorithm interpretation errors }\end{array}$ \\
\hline $\begin{array}{l}\text { Virginia } \\
\text { January } 2014 \text { individual level data } \\
\text { incorporated into EBC } \\
\text { CCHD diagnosis reported into BDR } \\
\text { Legislation mandates screening and } \\
\text { reporting for birth hospitals } \\
\text { Data collection mechanism: AG, EBC, } \\
\text { EMR, BDR }\end{array}$ & $\begin{array}{l}\text { Failure mode and effects analysis (FMEA) study } \\
\text { testing AAP algorithm improved screening } \\
\text { processes at each hospital } \\
\text { Majority of reported failed screens were } \\
\text { documentation errors. } \\
\text { QC activities include clarifying language in } \\
\text { EBC for more accurate reporting } \\
\text { Cross referencing EBC and BDR is essential to } \\
\text { identify children with CCHD. Most children } \\
\text { with CCHD reported to BDR were missing } \\
\text { screening results in EBC. Incomplete screening } \\
\text { results noted for prenatally diagnosed infants } \\
\text { Communication and education need for birth } \\
\text { registrars as well as providers in birth hospitals } \\
\text { Hospital site visits beneficial for QC and } \\
\text { education }\end{array}$ & $\begin{array}{l}\text { Staff turnover in birthing hospitals } \\
\text { specifically EBC registrars } \\
\text { Direct report of results into EBC, but no } \\
\text { automatic algorithm interpretation Registrars } \\
\text { required to interpret and document actual } \\
\text { result } \\
\text { Due to lack of funding, limited DOH staff to } \\
\text { conduct follow-up and referral } \\
\text { Reporting compliance } \\
\text { Missed screens for specific populations } \\
\text { Legislation does not mandate screening in } \\
\text { NICUs or for midwives } \\
\text { Continued funding needed to support } \\
\text { educational website }\end{array}$ \\
\hline $\begin{array}{l}\text { Wisconsin } \\
\text { CCHD screening and clinical data } \\
\text { linked to newborn hearing screening } \\
\text { surveillance } \\
\text { Newborn blood spot card used as the } \\
\text { data collection tool for CCHD Minimum } \\
\text { Data Set for all infants }\end{array}$ & $\begin{array}{l}\text { CCHD screening in the home birth community } \\
\text { was well received coincident with an increased } \\
\text { newborn blood screening rate } \\
\text { Mechanism to document reason for not } \\
\text { screening was needed to allow hospitals to } \\
\text { document compliance } \\
\text { Misinterpretation of screening algorithm } \\
\text { educational materials were beneficial }\end{array}$ & $\begin{array}{l}\text { Substantial manual data entry is required to } \\
\text { enter the Minimum } \\
\text { Data Set and to collect and enter the Expanded } \\
\text { Data Set } \\
\text { Reporting rates continue to vary significantly } \\
\text { between hospitals; ongoing education and QC } \\
\text { are required }\end{array}$ \\
\hline
\end{tabular}

Description of grantees' data collection Lessons learned

Continuing challenges activities
funding

Michigan

Data collection mechanism: EBC

MR, HL7, SEM, BDR

New England (ME, NH, VT, RI, CT)

$\mathrm{NH}$ and CT do not have public health

ies across five

level)

isconsin

Newborn blood spot card used as the Data Set for all infant trom birthing facilities, IT tments

follow-up on failed, missed and transferred cases

Screening at tertiary care centers has a very low detection rate, likely due to prenatal diagnosis

False positive rate is acceptably low Public cooperatively across states and shared resources,

Internal quality control (QC) audits needed at hospital leve

upport from

Individual level reporting improves ability to

for birthing facilities to EMR

BC reliable for Pass/Fail results and not

Need to work with legislature to include testing AAP algorithm improved screening

processes at each hospital

Majority of reported failed screens were Communication and registrars as well as providers in birth hospitals Hospital site visits beneficial for QC and cident with an increased document compliance educational materials were beneficial mpleteness, and Obtaining internal and external data use

Data are not collected consistently acros states and are reported in different formats care provided in bordering states No direct data input from EMR into electronic birth certificate and manual data entry required for individual level reporting No real-time QC of algorithm interpretation

Reporting errors by EBC clerk NICU results on most babie specifically EBC registrar utomatic algorithm interpretation Registrars result

Due to lack of funding, limited DOH staff to

for specific population mandate screening in

Continued funding needed to support

Substantial manual data entry is required to ter the Minimum

Reporting rates continue to vary significantly are required 


\begin{tabular}{cll}
\hline $\begin{array}{l}\text { Description of grantees' data collection } \\
\text { activities with demonstration grant } \\
\text { funding }\end{array}$ & Lessons learned & Continuing challenges \\
\hline Expanded Data Set collected on infants & Coordination of newborn blood, hearing, and & $\begin{array}{l}\text { Screening evaluation ends at the time of } \\
\text { diagnosis and no statewide evaluation of }\end{array}$ \\
who fail CCHD screening or are found to & $\begin{array}{l}\text { CCHD screening education, data collection, and } \\
\text { have CCHD }\end{array}$ & $\begin{array}{l}\text { SCHDeillance important } \\
\text { Data collection mechanism: EBC, }\end{array}$ \\
$\begin{array}{l}\text { Hospital specific reporting rates required to } \\
\text { evaluate implementation and effectiveness of } \\
\text { screening }\end{array}$ & \\
\hline
\end{tabular}

$A G$ aggregate data collection, $E B C$ electronic birth certificate, $B D R$ birth defects registry, $E M R$ hospital electronic medical record, $N B C$ newborn bloodspot card, SPF State-specific CCHD paper forms, SEM State-specific CCHD electronic module, HL7 Health level-7 messaging; automatic file transfer 